\title{
DIFERENTES TIPOS DE SECAGEM: EFEITOS NA QUALIDADE FISIOLÓGICA DE SEMENTES DE PINHÃO MANSO ${ }^{1}$
}

\author{
JOÃO BATISTA ZONTA 2 , EDUARDO FONTES ARAUJO ${ }^{3}$, ROBERTO FONTES ARAUJO ${ }^{4}$, \\ LUIZ ANTÔNIO DOS SANTOS DIAS ${ }^{3}$
}

\begin{abstract}
RESUMO - Objetivou-se no presente trabalho avaliar diferentes tipos de secagem e seus efeitos na qualidade fisiológica de sementes de pinhão manso (Jatropha curcas L.). As sementes, com teor de água de $32 \%$, foram secas à sombra até $9,9 \%$, ao sol até $8,8 \%$ e em estufa de circulação forçada às temperaturas de $33{ }^{\circ} \mathrm{C}$ até $8,5 \%$ e $43{ }^{\circ} \mathrm{C}$ até $8,3 \%$ A qualidade fisiológica das sementes foi avaliada pelos testes de germinação, primeira contagem de germinação, condutividade elétrica, envelhecimento acelerado, emergência em areia e índice de velocidade de emergência. A temperatura de $43{ }^{\circ} \mathrm{C}$ proporcionou secagem mais rápida das sementes, com duração de 42 horas. Nas secagens a $33{ }^{\circ} \mathrm{C}$, ao sol e a sombra, este período foi mais prolongado, com 54, 144 e 456 horas, respectivamente. A secagem à sombra proporcionou redução na qualidade fisiológica das sementes. As sementes secadas ao sol ou à temperatura de $33{ }^{\circ} \mathrm{C}$ não diferiram entre si quanto à qualidade fisiológica e foram superiores àquelas secadas à sombra; entretanto, a germinação foi inferior àquelas secadas a $43^{\circ} \mathrm{C}$, a partir dos 180 dias de armazenamento. A secagem à temperatura de $43{ }^{\circ} \mathrm{C}$ não afetou a germinação das sementes e reduziu ligeiramente o vigor, mesmo após 270 dias de armazenamento. Como a maior temperatura utilizada não afetou a germinação das sementes, isto sugere ter sido o tempo gasto na secagem das sementes é determinante para sua conservação. Sementes de pinhão manso podem ser secadas ao sol e sob temperaturas de 33 e 43 ${ }^{\circ} \mathrm{C}$; temperatura de $43{ }^{\circ} \mathrm{C}$ proporciona menor tempo de secagem e melhor germinação e vigor de sementes de pinhão manso; secagem à sombra é prejudicial à qualidade de sementes de pinhão manso.
\end{abstract}

Termos para indexação: Jatropha curcas L., germinação, deterioração, qualidade fisiológica, conservação

\section{EFFECTS OF DIFFERENT TYPES OF DRYING ON THE PHYSIOLOGICAL QUALITY OF PHYSIC NUT SEEDS}

\begin{abstract}
This study aimed to evaluate different types of drying and their effects on the physiological quality of physic nut seeds (Jatropha curcas L.). Seeds with $32 \%$ water content were dried in the shade to $9.9 \%$, in the sun to $8.8 \%$, in a forced circulation oven, at a temperature of $33{ }^{\circ} \mathrm{C}$, to $8.5 \%$ and at $43{ }^{\circ} \mathrm{C}$ to $8.3 \%$ water content. The physiological seed quality was evaluated by germination, first count of germination, electrical conductivity and accelerated aging tests, as well as the seedling emergence index and emergence rate. A temperature of $43{ }^{\circ} \mathrm{C}$ dries seeds faster and lasts 42 hours. The drying period at $33^{\circ} \mathrm{C}$ in the sun and shade lasted longer, at 54,144 and 456 hours respectively. Shade drying caused an immediate reduction in physiological seed quality. Those seeds dried in the sun or at a temperature of $33^{\circ} \mathrm{C}$ showed no differences regarding physiological status and were better than those dried in the shade. However, germination was
\end{abstract}

${ }^{1}$ Submetido em 02/12/10. Aceito para publicação em 22/04/11. Parte de tese de Doutorado do primeiro autor.

${ }^{2}$ Dr., Analista B, Embrapa Cocais, 65046-660, São Luís - MA: e-mail: joao.zonta@embrapa.br

${ }^{3}$ Dr., Professor Associado, Departamento de Fitotecnia Universidade
Federal de Viçosa, 36570-000, Viçosa - MG: e-mails: efaraujo@ufv.br, lasdias@ufv.br

${ }^{4}$ Dr., Pesquisador EPAMIG/CTZM, 36570-000, Viçosa - MG; e-mail: rfaraujo@ufv.br 
lower than for seeds dried at $43{ }^{\circ} \mathrm{C}$ after 180 days storage. A drying temperature of $43{ }^{\circ} \mathrm{C}$ did not affect seed germination and only slightly reduced the vigor, even after 270 days storage. As the highest temperature used did not affect seed germination, it is suggested that seed drying time was crucial to its conservation. Physic nut seeds can be dried in the sun and in temperatures of 33 and $43{ }^{\circ} \mathrm{C}$; a temperature of $43{ }^{\circ} \mathrm{C}$ results in a shorter drying time and a better germination and seed vigor of the physic nut whereas shade drying is detrimental to seed quality.

Index terms: Jatropha curcas L., germination, deterioration, physiological quality, conservation.

\section{INTRODUÇÃO}

O pinhão manso (Jatropha curcas L.) é uma planta arbórea da família Euphorbiaceae que pode apresentar até $5 \mathrm{~m}$ de altura, é perene, semidecídua, monóica e produz um abundante suco lácteo. Seu fruto é uma cápsula que contém três sementes escuras, lisas, dentro das quais se encontram as amêndoas brancas, tenras e ricas em óleo (Luo et al., 2007; Sirisomboon et al., 2007). Devido ao alto teor de óleo encontrado nas sementes (até 39,8\%), destaca-se como uma planta com grande potencial para a produção de biodiesel (Shaochun et al., 2007).' Mas em função deste óleo, as sementes não podem ser armazenadas por longos períodos. São classificadas como ortodoxas, permitindo secagem a baixos teores de água (Joker e Jepsen, 2003; Morais, 2008).

Vários fatores podem interferir na qualidade das sementes durante o processo de produção, $v$, destacandose, entre eles, as condições predominantes durante a maturação, a colheita, o beneficiamento, o manuseio, a secagem e o armazenamento. Nesse sentido, a redução do teor de água das sementes como resultado da secagem atua diretamente na diminuição do metabolismo, o que pode contribuir para diminuir a taxa de deterioração e aumentar o período em que podem ser armazenadas, sem perda da qualidade fisiológica. Ainda, o teor de água das sementes tem relação direta com a atividade de insetos e microrganismos e estes com as sementes (Marcos Filho, 2005).

A secagem de sementes, além de contribuir para a preservação da qualidade fisiológica durante $o$ armazenamento, possibilita a antecipação da colheita, evitando perdas de natureza diversa durante o processo produtivo. A secagem pode ser realizada de forma natural ou artificial. Na escolha do método de secagem, o volume de sementes é fator limitante. Para grandes quantidades de sementes, é imprescindível a utilização de secagem artificial, cujos custos de operação estão diretamente relacionados com o volume, a velocidade de secagem e a temperatura do ar (Garcia et al., 2004). Na secagem artificial, a fonte de calor pode ser variável. O que caracteriza o método como artificial é o fato de que o processo é executado com o auxílio de alternativas mecânicas, elétricas ou eletrônicas e o ar é forçado através da massa de sementes (Cavariani, 1996). A secagem natural é baseada nas ações do vento e do sol para a remoção da umidade das sementes. Tal processo é limitado pelo clima, quando as condições de umidade relativa do ar e temperatura não permitem, ou quando se trata de maiores volumes de sementes (Maia, 1995).

Em geral, recomenda-se que a secagem de sementes seja realizada de tal forma que a temperatura delas não ultrapasse $40{ }^{\circ} \mathrm{C}$, para que não haja redução acentuada de sua qualidade fisiológica. No entanto, a temperatura máxima às quais as sementes podem ser expostas, durante a secagem, depende do seu teor de água e do tempo de exposição a essa condição. Harrington (1959), apud Ahrens et al. (2000) propôs os seguintes limites: sementes com teores de água superiores a $18 \%$, a temperatura na massa de sementes deve ser no máximo $32{ }^{\circ} \mathrm{C}$; entre 10 e $18 \%$ até $38{ }^{\circ} \mathrm{C}$ e abaixo de $10 \%$ pode ser empregada a temperatura máxima de $43{ }^{\circ} \mathrm{C}$. Para sementes de mamona, oleaginosa com características semelhantes as do pinhão manso, Moshkin (1986) afirma que a temperatura de secagem suportada pela massa de sementes não deve ser superior a $45^{\circ} \mathrm{C}$

Apesar das vantagens que apresenta, a secagem é uma operação potencialmente danosa à qualidade das sementes e depende do correto manejo dos teores de água inicial e final das sementes, da temperatura, da umidade relativa, fluxo de ar, da taxa de secagem e do período de exposição ao ar aquecido (Miranda et al., 1999). Os danos térmicos podem não manifestar efeitos imediatos na germinação, contudo, após um período de armazenamento, o vigor das sementes 
pode sofrer reduções consideráveis (Popinigis, 1985).

Para sementes de pinhão manso, Ullmann et al. (2010) citam que estas podem ser secadas artificialmente sob temperaturas de $30,40,50$ e $60{ }^{\circ} \mathrm{C}$ sem haver prejuízo imediato na porcentagem de germinação. Em relação ao efeito latente, não há relatos na literatura.

Tendo em vista a escassez de informações relevantes sobre o processo de secagem em sementes de pinhão manso, desenvolveu-se este trabalho com o objetivo de avaliar os efeitos imediatos e latentes das condições de secagem na qualidade fisiológica de sementes de pinhão manso.

\section{MATERIAL E MÉTODOS}

O experimento foi conduzido no Laboratório de Pesquisa em Sementes do Departamento de Fitotecnia da Universidade Federal de Viçosa, Viçosa-MG, nos anos de 2009 e 2010. Para tanto, foram utilizadas sementes de pinhão manso (Jatropha curcas L.) provenientes da Empresa de Pesquisa Agropecuária de Minas Gerais (EPAMIG), coletadas no município de Janaúba - MG.

Após a colheita, frutos de pinhão manso maduros, com coloração amarela, cujas sementes, que medem cerca de 1,5 a $2 \mathrm{~cm}$ de comprimento e 1,0 a $1,3 \mathrm{~cm}$ de largura, apresentam tegumentos com coloração marrom escuro, foram descascados à mão. Posteriormente foram transportados da Unidade Regional Epamig Norte de Minas, em Janaúba-MG, para a Unidade Regional Epamig Zona da Mata, em Viçosa-MG.

Imediatamente após o recebimento, determinou-se o teor de água das sementes pelo método da estufa a $105 \pm 3$ ${ }^{\circ} \mathrm{C}$, durante 24 horas, conforme as Regras para Análise de Sementes (Brasil, 2009), utilizando-se três amostras de 15 sementes intactas. As sementes apresentavam teor de água inicial de aproximadamente $32 \%$.

Foram utilizados os seguintes tratamentos de secagem: secagem à sombra, secagem ao sol e secagem artificial em estufa de ventilação forçada sob temperaturas de $33{ }^{\circ} \mathrm{C}$ e $43{ }^{\circ} \mathrm{C}$. Para as secagens a sombra e ao sol, as condições ambientais observadas no momento da secagem eram de $23{ }^{\circ} \mathrm{C}$ e $83 \%$ de umidade relativa. $\mathrm{O}$ teor de água das sementes foi acompanhado por diferença em peso, utilizando-se cinco subamostras de sementes acondicionas em sacos de filó, com massa e umidade iniciais conhecidas. Durante a secagem, em intervalos de 30 minutos, os sacos de filó com as sementes eram pesados até atingirem as massas finais desejadas, correspondentes aos teores de água finais.

Ao final do processo de secagem, uma amostra de sementes foi retirada para determinação do teor de água final, pelo método da estufa descrito anteriormente. O restante do material foi utilizado para realização dos testes de avaliação da qualidade fisiológica. Imediatamente após a secagem foram realizados testes de germinação e vigor, para avaliar os efeitos imediatos das condições de secagem. Para avaliar o efeito latente, os testes foram realizados aos 90, 180 e 270 dias de armazenamento das sementes.

A porção de sementes destinada à avaliação do efeito latente foi acondicionada em sacos de pano, sendo armazenadas em câmara fria a $18{ }^{\circ} \mathrm{C}$ e $60-65 \%$ de umidade relativa. Para verificação da ocorrência de variação no teor de água ao longo do tempo, o teor de água das sementes foi determinado ao final de cada período de armazenamento.

$\mathrm{O}$ teste de germinação foi conduzido com oito repetições de 25 sementes, utilizando-se como substrato rolo de papel germitest, umedecido com água destilada na proporção de 2,5 vezes seu peso seco. Os rolos foram mantidos em câmara de germinação, à temperatura constante de $30^{\circ} \mathrm{C}$. As avaliações foram realizadas aos 5 e 10 dias, considerando-se germinadas as sementes com protrusão de raiz primária igual ou superior a $2,0 \mathrm{~cm}$ e que apresentassem pelo menos três raízes secundárias (Martins et al, 2008). No momento da montagem do teste de germinação, as sementes foram tratadas com fungicida Captan, sendo utilizados 2,4 $\mathrm{g}$ de produto por $1000 \mathrm{~g}$ de semente.

Para determinação do vigor, foram realizados os testes de primeira contagem de germinação, condutividade elétrica, envelhecimento acelerado e emergência em areia, no qual foram obtidos os valores de percentagem e índice de velocidade de emergência.

A primeira contagem do teste de germinação foi realizada conjuntamente com o teste de germinação e consistiu da contagem de plântulas normais no quinto dias após a instalação do teste, sendo os resultados expressos em porcentagem.

O teste de condutividade elétrica da solução de embebição das sementes foi conduzido pelo sistema de massa (Vieira e Krzyzanowski, 1999), com oito repetições de 15 sementes intactas, previamente pesadas em balança de precisão. As sementes foram colocadas em copos plásticos com capacidade para $200 \mathrm{~mL}$, nos quais foram adicionados $75 \mathrm{~mL}$ de água destilada. Os copos contendo as sementes e a água foram colocados em câmara de 
germinação (tipo BOD) a $25^{\circ} \mathrm{C}$, durante 6 horas, sendo então realizadas as leituras de condutividade elétrica da solução de embebição das sementes utilizando-se de condutivímetro (DIGIMED DM 31), com os resultados expressos em $\mu \mathrm{S} . \mathrm{cm}^{-1} \cdot \mathrm{g}^{-1}$.

O teste de envelhecimento acelerado foi conduzido com oito repetições de 25 sementes, adaptando-se a metodologia proposta por Marcos Filho (1999). Foram utilizadas caixas plásticas transparentes com tampas (gerbox) com $11 \times 11 \times 3 \mathrm{~cm}$, adaptadas como minicâmaras, dentro das quais foram adicionados $40 \mathrm{~mL}$ de água destilada. Acima da água, foi colocada uma tela e sobre esta, em cada caixa, foram colocadas 55 sementes de modo que, para cada tratamento foram utilizadas quatro caixas. Em seguida, as caixas plásticas foram levadas para a câmara do tipo BOD, regulada na temperatura de $42{ }^{\circ} \mathrm{C}$, onde permaneceram por 48 horas. Ao final do período de envelhecimento, as caixas plásticas foram retiradas da câmara e as sementes submetidas ao teste de germinação. Estes foram realizados conforme metodologia anteriormente descrita para o teste de germinação. No momento da realização do teste de germinação, as sementes foram tratadas com fungicida Captan, na dosagem de 2,4 $\mathrm{g}$ de produto por $1.000 \mathrm{~g}$ de semente.

$\mathrm{O}$ teste de emergência em areia foi conduzido em casa de vegetação, sendo a areia anteriormente lavada e esterilizada em estufa a $200{ }^{\circ} \mathrm{C}$, durante duas horas. As sementes foram semeadas em bandejas plásticas a três $\mathrm{cm}$ de profundidade. A umidade do substrato foi mantida com irrigações, realizadas diariamente. Foram utilizadas oito repetições de 30 sementes por tratamento. A contagem foi realizada a partir da emergência da primeira plântula e prosseguiu até a estabilização das contagens. Na ultima contagem, foi determinado o percentual de plântulas emergidas. Conjuntamente com o teste de emergência em areia foi determinado o índice de velocidade de emergência, computando-se no mesmo horário, o número de plântulas que apresentaram cotilédones visíveis. O índice foi calculado empregando-se a fórmula proposta por (Maguire 1962).

O experimento foi instalado em delineamento inteiramente casualizado, com oito repetições, sendo as médias dos tratamentos, dentro de cada período de avaliação, comparadas pelo teste de Tukey, ao nível de $5 \%$ de probabilidade. Para avaliação dos efeitos dos tratamentos durante o período de armazenamento, os dados foram submetidos à análise de regressão polinomial. Também foi realizada análise de regressão para estudar o efeito do tempo de secagem na qualidade fisiológica das sementes. Para análise dos dados foi utilizado o Sistema de Análises Estatísticas e Genéticas - SAEG (Saeg, 2007).

\section{RESULTADOS E DISCUSSÃO}

O teor de água das sementes obtido no final do processo de secagem e o tempo gasto nessa operação são apresentados na Tabela 1. Para os métodos de secagem ao sol e em estufa a 33 e $43{ }^{\circ} \mathrm{C}$, a secagem das sementes foi realizada até estas alcançarem teores de água de $8,8 \%, 8,5 \%$ e $8,3 \%$, respectivamente. Para as sementes secadas a sombra, as condições climáticas do ambiente não permitiram a secagem até o referido nível e, assim, as sementes apresentaram $10 \%$ de teor de água. Em relação ao tempo necessário para as sementes atingirem o teor de água desejado, nota-se que a secagem em estufa proporcionou secagem mais rápida das sementes, em ambas as temperaturas utilizadas, quando comparada aos tratamentos de secagem natural (sol e sombra). Para a secagem em estufa sob temperaturas de $33{ }^{\circ} \mathrm{C}$ e $43{ }^{\circ} \mathrm{C}$, o tempo gasto na secagem foi de 54 e 42 horas respectivamente. Já para as secagens à sombra e ao sol, o tempo gasto foi de 456 e 144 horas, respectivamente. Assim, nota-se que o tempo gasto na secagem em estufa a $43{ }^{\circ} \mathrm{C}$ foi mais de 10 vezes superior ao gasto na secagem à sombra, evidenciando que o aumento da temperatura e o uso de ventilação forçada reduzem o tempo gasto no processo. Sirisomboon e Kitchaiya (2009) secando sementes de pinhão manso nas temperaturas do ar de secagem de $40{ }^{\circ} \mathrm{C}, 60{ }^{\circ} \mathrm{C}$ e $80{ }^{\circ} \mathrm{C}$ observaram que com o aumento da temperatura ocorreu diminuição no tempo de secagem. Resultados semelhantes também foram observados por Ahrens et al. (2000) e Ullmann et al. (2010) que verificaram diminuição no período de secagem com o aumento da temperatura. Durante o armazenamento no presente experimento, as sementes entraram em equilíbrio higroscópico com o ar ambiente, atingindo e mantendo o teor de água em torno de 7,5\% (dados não apresentados).

Analisando os resultados de germinação das sementes (Tabela 2), observou-se efeito imediato da secagem a sombra, a qual proporcionou uma redução de aproximadamente $20 \%$ na germinação das sementes, quando comparada aos demais métodos de secagem. Esses resultados mostram que o período prolongado de tempo proporcionado pelo método de secagem a sombra, muito provavelmente favoreceu um processo de envelhecimento acelerado, com perda acentuada da 
capacidade germinativa das sementes de pinhão manso.

Tal fato foi também constatado por outros, com feijão
(Ahrens e Lolatto, 1995) e com soja (Miranda et al., 1999); com azevém (Eichelberger et al., 2003), entre outros.

TABELA 1. Tempo de secagem e teor de água final das sementes de pinhão manso, nas diferentes condições de secagem.

\begin{tabular}{ccc}
\hline Condições de Secagem & Tempo (horas) & Teor de água final (\%) \\
\hline Sombra & 456 & 9,9 \\
Sol & 144 & 8,8 \\
$33^{\circ} \mathrm{C}$ & 54 & 8,5 \\
$43{ }^{\circ} \mathrm{C}$ & 42 & 8,3 \\
\hline
\end{tabular}

TABELA 2. Germinação e vigor de sementes de pinhão manso submetidas a diferentes condições de secagem e períodos de armazenamento.

\begin{tabular}{|c|c|c|c|c|}
\hline $\begin{array}{l}\text { Condições de } \\
\text { Secagem }\end{array}$ & $\begin{array}{c}\text { Período de } \\
\text { Armazenamento }\end{array}$ & Germinação (\%) & Primeira Contagem $(\%)$ & $\begin{array}{c}\text { Envelhecimento } \\
\text { Acelerado (\%) }\end{array}$ \\
\hline Sombra & \multirow{4}{*}{ Início } & $78 b^{1}$ & $70 \mathrm{~b}$ & $61 b^{1}$ \\
\hline Sol & & 99 a & $93 \mathrm{a}$ & $96 \mathrm{a}$ \\
\hline $33^{\circ} \mathrm{C}$ & & $98 \mathrm{a}$ & $96 \mathrm{a}$ & $91 \mathrm{a}$ \\
\hline $43{ }^{\circ} \mathrm{C}$ & & $97 \mathrm{a}$ & $93 \mathrm{a}$ & $96 \mathrm{a}$ \\
\hline Sombra & \multirow{4}{*}{90 dias } & $67 \mathrm{~b}$ & $62 \mathrm{~b}$ & $57 \mathrm{c}$ \\
\hline Sol & & $96 \mathrm{a}$ & $85 \mathrm{a}$ & $86 \mathrm{~b}$ \\
\hline $33^{\circ} \mathrm{C}$ & & $97 \mathrm{a}$ & $85 \mathrm{a}$ & $89 \mathrm{ab}$ \\
\hline $43^{\circ} \mathrm{C}$ & & $97 \mathrm{a}$ & $92 \mathrm{a}$ & $95 \mathrm{a}$ \\
\hline Sombra & \multirow{4}{*}{180 dias } & $43 \mathrm{~b}$ & $27 \mathrm{~b}$ & $39 \mathrm{~b}$ \\
\hline Sol & & $79 \mathrm{a}$ & $66 \mathrm{a}$ & $65 \mathrm{a}$ \\
\hline $33^{\circ} \mathrm{C}$ & & $76 \mathrm{a}$ & $60 \mathrm{a}$ & $67 \mathrm{a}$ \\
\hline $43^{\circ} \mathrm{C}$ & & $85 \mathrm{a}$ & $74 \mathrm{a}$ & $73 \mathrm{a}$ \\
\hline Sombra & \multirow{4}{*}{270 dias } & $43 \mathrm{c}$ & $27 \mathrm{~b}$ & $36 \mathrm{~b}$ \\
\hline Sol & & $79 \mathrm{~b}$ & $66 \mathrm{a}$ & $65 \mathrm{a}$ \\
\hline $33^{\circ} \mathrm{C}$ & & $76 \mathrm{~b}$ & $60 \mathrm{a}$ & $67 \mathrm{a}$ \\
\hline $43{ }^{\circ} \mathrm{C}$ & & 89 a & $69 a$ & $75 \mathrm{a}$ \\
\hline
\end{tabular}

${ }^{1}$ Para cada período de armazenamento, médias seguidas pela mesma letra na coluna não diferem estatisticamente entre si, pelo teste de Tukey ao nível de $5 \%$ de probabilidade.

Quanto aos demais métodos de secagem, não houve diferenças significativas na capacidade germinativa das sementes quando avaliados logo após a secagem, com ambos os tratamentos apresentando germinação em torno de $98 \%$ (Tabela 2). Esses resultados mostram que a secagem em estufa à temperatura de $33{ }^{\circ} \mathrm{C}$ e $43{ }^{\circ} \mathrm{C}$ e a secagem ao sol não causam danos imediatos às sementes de pinhão manso. Corroborando com os resultados, Ullmann et al. (2010) observaram que a secagem de sementes de pinhão manso à temperatura de $30{ }^{\circ} \mathrm{C}$ e $40{ }^{\circ} \mathrm{C}$ não foi prejudicial à germinação das sementes. Harrington (1972) afirma que a temperatura máxima para a secagem segura de sementes depende da espécie, mas geralmente varia de $35^{\circ} \mathrm{C}$ a $45^{\circ} \mathrm{C}$, sendo que, para sementes parcialmente secas, essa temperatura pode ser mais elevada. Barbedo et al. (2002) submeteram sementes de Caesalpinia echinata (pau-brasil) à secagem em estufas reguladas a $40{ }^{\circ} \mathrm{C}$ e $50{ }^{\circ} \mathrm{C}$, reduzindo teor 
de água até $8 \%$, e não constataram efeitos negativos da temperatura de secagem sobre a germinação das sementes. Para sementes de mamona, oleaginosa de características semelhantes as do pinhão manso, Moshkin (1986) afirma que a temperatura de secagem suportada pela massa de sementes não deve ser superior a $45{ }^{\circ} \mathrm{C}$.

Quanto ao efeito da secagem na germinação das sementes durante o armazenamento (Tabela 2), nas avaliações realizadas aos 90 e 180 dias, as sementes secadas ao sol ou em estufa, tanto a $33{ }^{\circ} \mathrm{C}$ como a $43{ }^{\circ} \mathrm{C}$, não diferiram significativamente entre si e foram ambos superiores a secagem à sombra. Para a avaliação realizada aos 270 dias, as sementes secadas a $43{ }^{\circ} \mathrm{C}$ apresentaram porcentagem de germinação de aproximadamente $90 \%$. Para as demais condições de secagem, o maior decréscimo foi observado para as sementes secadas à sombra, que apresentaram germinação de $43 \%$, aos 270 dias de armazenamento. Já para as sementes secadas ao sol e em estufa a $33{ }^{\circ} \mathrm{C}$, a germinação permaneceu acima de $75 \%$, o que em termos práticos pode ser considerado satisfatório, já que a espécie ainda não possui padrões de produção e comercialização de sementes.

Observando-se o desempenho germinativo das sementes ao longo do armazenamento (Figura 1), observase que, para as sementes secadas a sombra, ao sol e em estufa a $33{ }^{\circ} \mathrm{C}$ houve decréscimo linear e significativo na germinação. Para as sementes secadas em estufa a $43^{\circ} \mathrm{C}$, não houve decréscimo no poder germinativo ao longo do armazenamento, com as sementes mantendo, aos 270 dias, quando avaliados por regressão linerar. Mas na Tabela 2 pode-se verificar que a germinacão inicial de $97 \%$ baixou para $89 \%$ durante 270 dias de armazenamento.
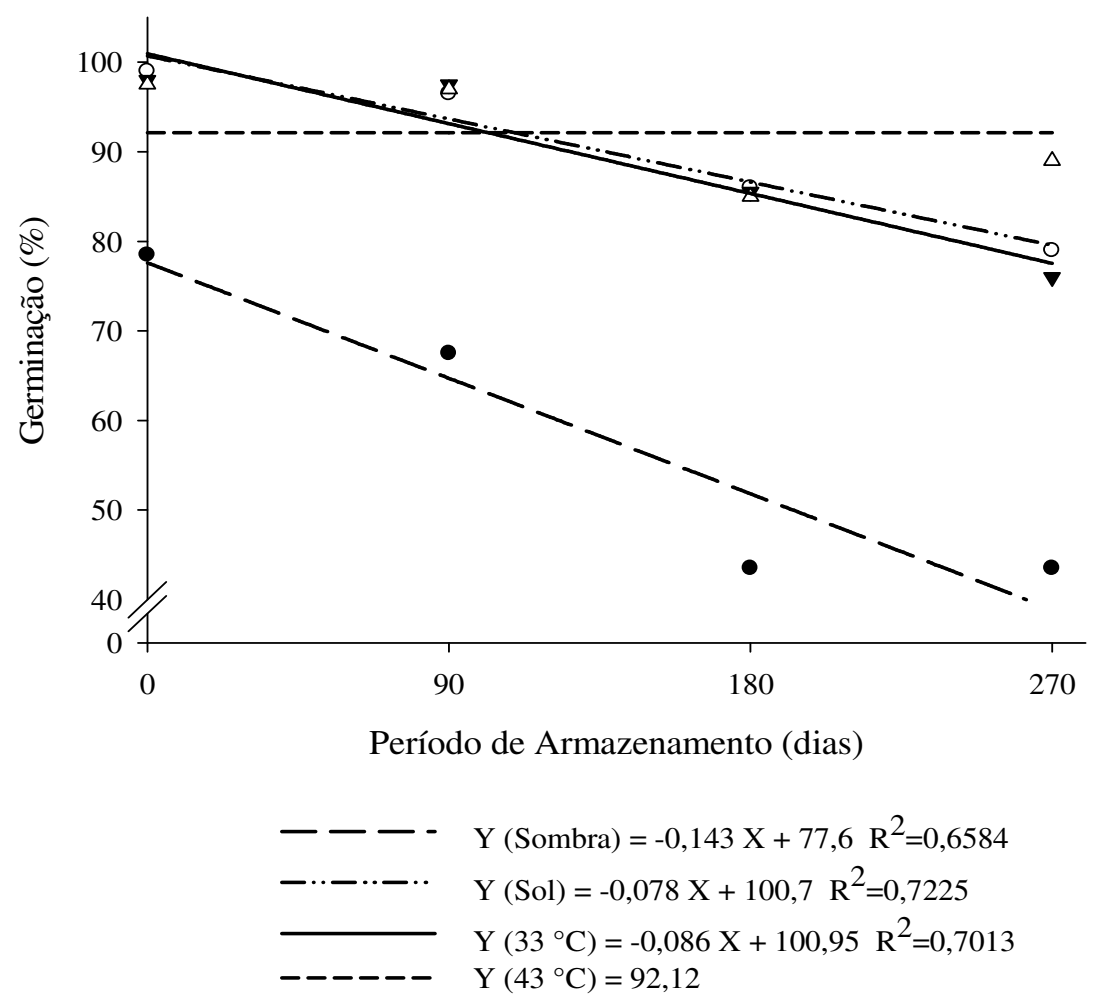

FIGURA 1. Germinação de sementes de pinhão manso submetidas a diferentes condições de secagem e períodos de armazenamento.

Quanto ao efeito imediato da secagem no vigor das sementes, verificou-se que a secagem à sombra influenciou negativamente o vigor das sementes, em todos os testes realizados. Nos demais tratamentos de secagem pode-se afirmar que as sementes apresentaram alto vigor, verificado pelos valores obtidos nos testes de primeira contagem, de envelhecimento acelerado e de emergência em areia, os quais foram semelhantes àqueles observados no teste de germinação (Tabelas 2 e 3). Quanto ao efeito da secagem no vigor das sementes ao longo do armazenamento (90, 180 e 270 dias), observou-se que foi mantido o padrão observado na avaliação realizada 
imediatamente após a secagem, sendo que as sementes secadas à sombra apresentaram valores estatisticamente inferiores aos das sementes secadas sob temperaturas de 33 e $43{ }^{\circ} \mathrm{C}$, em todos os testes de vigor (Tabelas 2 e 3). Em relação ao vigor das sementes ao longo do armazenamento os resultados dos testes de primeira contagem de germinação, envelhecimento acelerado e condutividade elétrica (Figuras 2, 3 e 4) apresentaram decréscimo linear, em todos os tratamentos de secagem. No teste de emergência em areia não houve decréscimo no vigor das sementes submetidas aos tratamentos, sendo que o resultado das ultimas avaliações (270 dias) apresentaram valores significativamente iguais aos observados antes do armazenamento. Os resultados do teste de emergência e de índice de velocidade de emergência (IVE) não foram analisados ao longo do armazenamento, uma vez que o teste foi realizado em casa de vegetação e, portanto, em condições de ambiente não controlado. Nas diferentes épocas de realização dos testes de emergência em areia, as condições de temperatura e luminosidade são diferentes, o que pode interferir nas avaliações. Os valores de emergência e de IVE das sementes de diferentes tratamentos de secagem, ao longo do armazenamento, foram analisados somente para comparar os tratamentos de secagem dentro de cada período de avaliação (Tabela 3).

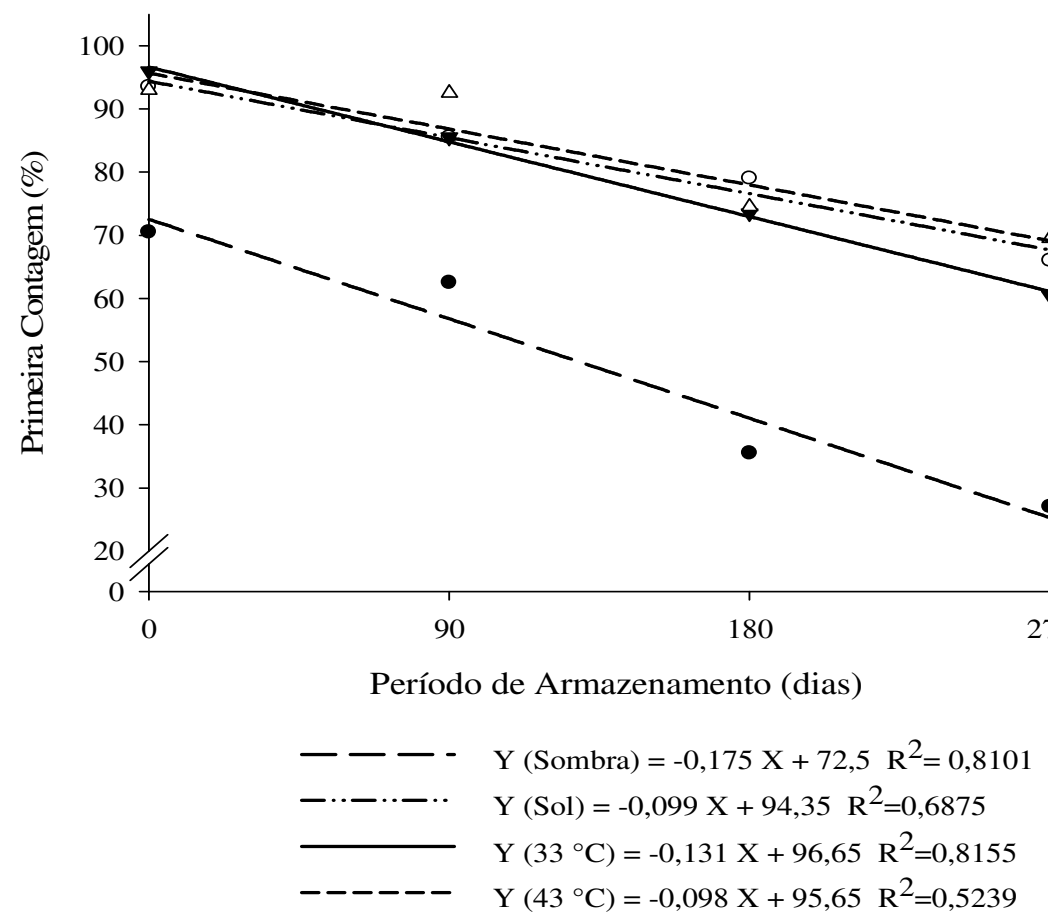

FIGURA 2. Vigor, pelo teste de primeira contagem de germinação, de sementes de pinhão manso submetidas a diferentes condições de secagem e períodos de armazenamento.

De maneira geral foi observado que, tanto na secagem em estufa, a 33 e $43{ }^{\circ} \mathrm{C}$, quanto na secagem ao sol, as sementes apresentaram alta porcentagem de germinação inicial, tendo as sementes secadas a $43{ }^{\circ} \mathrm{C}$ mantido o potencial de germinação ao longo do armazenamento. As sementes secadas em estufa a $33^{\circ} \mathrm{C}$ e ao sol apresentaram decréscimo na porcentagem de germinação. Quanto ao vigor, as sementes secadas em estufa a $33{ }^{\circ} \mathrm{C}$ e $43{ }^{\circ} \mathrm{C}$ e ao sol apresentaram, em todos os períodos de avaliação, resultados semelhantes. Conseqüentemente, a secagem em estufa a $43{ }^{\circ} \mathrm{C}$ é a mais indicada para sementes de pinhão manso, uma vez que proporciona maior rapidez no processo. 


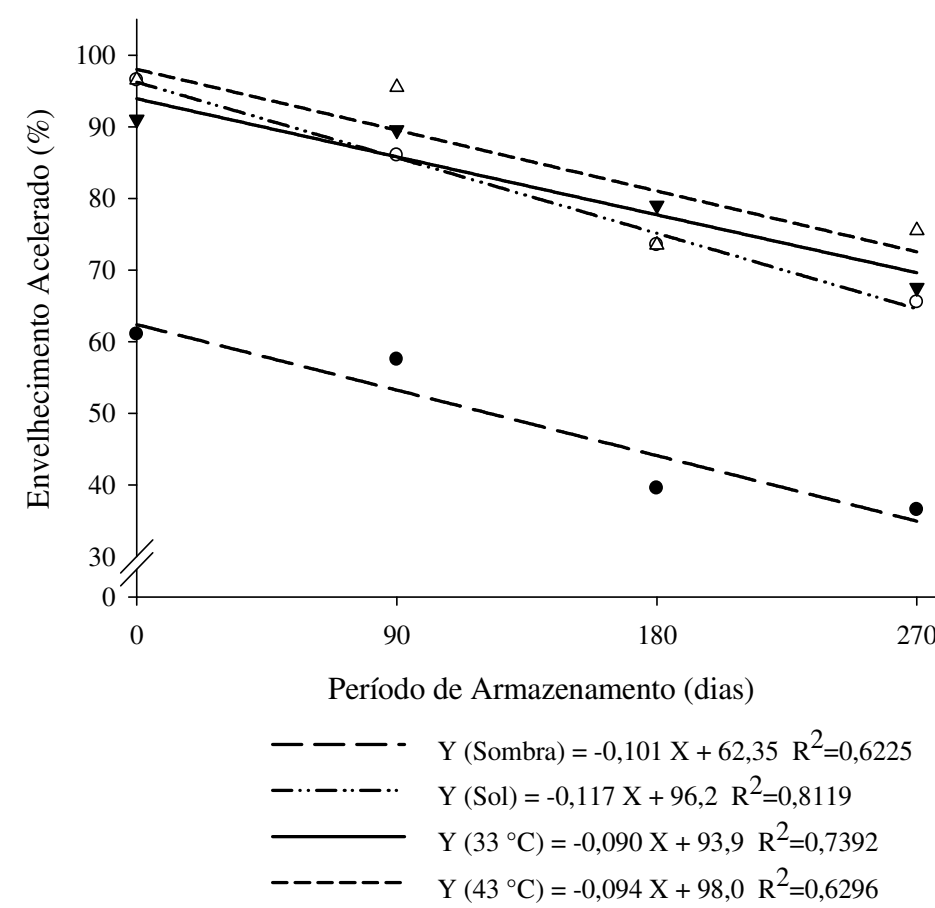

FIGURA 3. Vigor, pelo teste de envelhecimento acelerado, de sementes de pinhão manso, submetidas a diferentes condições de secagem e períodos de armazenamento.

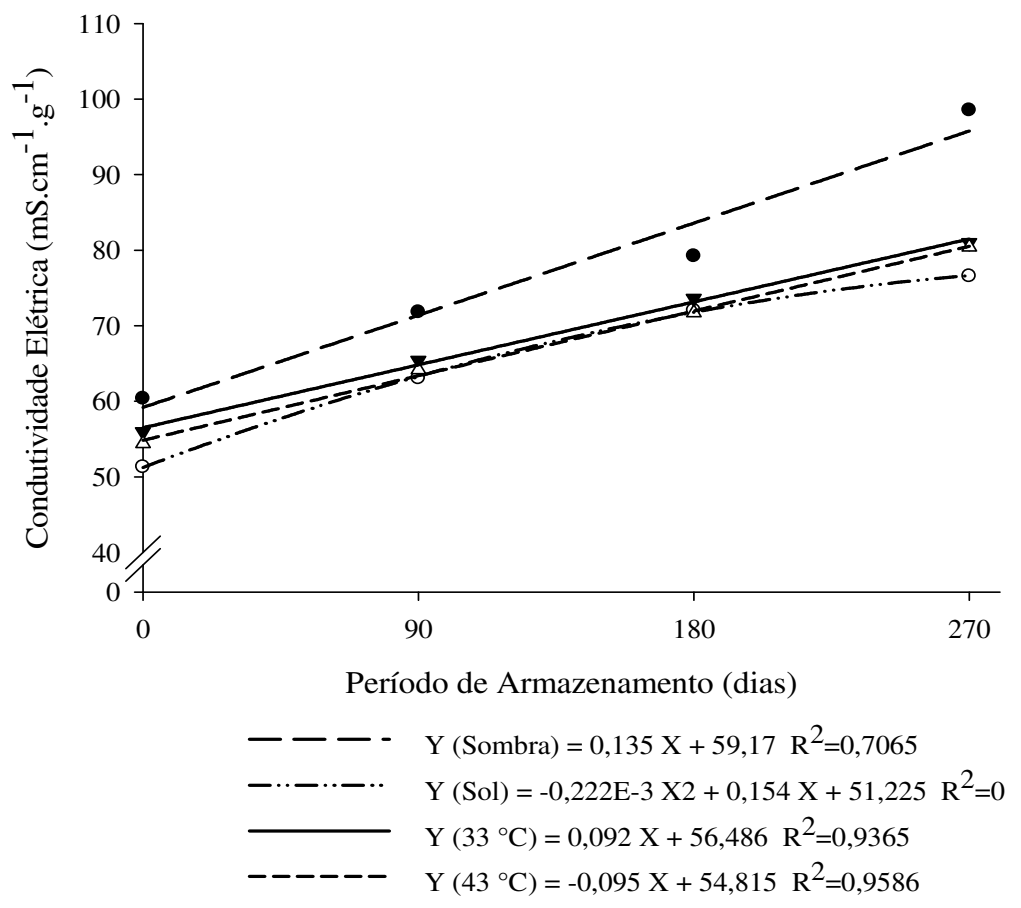

FIGURA 4. Vigor, pelo teste de condutividade elétrica, de sementes de pinhão manso submetidas a diferentes condições de secagem e períodos de armazenamento. 
TABELA 3. Vigor, pelos testes de condutividade elétrica, emergência em areia e índice de velocidade de emergência, de sementes de pinhão manso submetidas a diferentes condições de secagem e períodos de armazenamento.

\begin{tabular}{|c|c|c|c|c|}
\hline $\begin{array}{l}\text { Condições de } \\
\text { Secagem }\end{array}$ & $\begin{array}{c}\text { Período de } \\
\text { Armazenamento }\end{array}$ & $\begin{array}{l}\text { Condutividade elétrica } \\
\left(\mu \mathrm{S} \cdot \mathrm{cm}^{-1} \cdot \mathrm{g}^{-1}\right)\end{array}$ & $\begin{array}{c}\text { Emergência em Areia } \\
(\%)\end{array}$ & IVE \\
\hline Sombra & \multirow{4}{*}{ Início } & $60,34 \mathrm{a}$ & $72 b^{1}$ & $2,233 \mathrm{c}$ \\
\hline Sol & & $51,30 \mathrm{c}$ & $98 \mathrm{a}$ & $2,670 \mathrm{~b}$ \\
\hline $33^{\circ} \mathrm{C}$ & & $55,95 \mathrm{~b}$ & $99 a$ & $2,030 \mathrm{ab}$ \\
\hline $43^{\circ} \mathrm{C}$ & & $54,37 \mathrm{bc}$ & $99 \mathrm{a}$ & $3,037 \mathrm{a}$ \\
\hline Sombra & \multirow{4}{*}{90 dias } & $71,80 \mathrm{a}$ & $66 \mathrm{~b}$ & $2,442 \mathrm{~b}$ \\
\hline Sol & & $63,04 \mathrm{~b}$ & $97 a$ & $3,594 \mathrm{a}$ \\
\hline $33^{\circ} \mathrm{C}$ & & $65,39 \mathrm{~b}$ & $97 \mathrm{a}$ & $3,646 \mathrm{a}$ \\
\hline $43^{\circ} \mathrm{C}$ & & $64,16 \mathrm{~b}$ & $97 \mathrm{a}$ & $3,631 \mathrm{a}$ \\
\hline Sombra & \multirow{4}{*}{180 dias } & $79,21 \mathrm{a}$ & $62 \mathrm{~b}$ & $2,119 \mathrm{~b}$ \\
\hline Sol & & $72,01 \mathrm{~b}$ & $90 \mathrm{a}$ & $3,678 \mathrm{a}$ \\
\hline $33^{\circ} \mathrm{C}$ & & $73,60 \mathrm{~b}$ & $91 \mathrm{a}$ & $3,555 \mathrm{a}$ \\
\hline $43^{\circ} \mathrm{C}$ & & $71,68 \mathrm{~b}$ & $97 \mathrm{a}$ & $3,651 \mathrm{a}$ \\
\hline Sombra & \multirow{4}{*}{270 dias } & $98,53 \mathrm{a}$ & $63 \mathrm{~b}$ & $2,108 \mathrm{~b}$ \\
\hline Sol & & $76,55 \mathrm{~b}$ & $90 \mathrm{a}$ & $2,862 \mathrm{a}$ \\
\hline $33^{\circ} \mathrm{C}$ & & $80,98 \mathrm{~b}$ & $91 \mathrm{a}$ & $2,895 \mathrm{a}$ \\
\hline $43^{\circ} \mathrm{C}$ & & $80,41 \mathrm{~b}$ & $95 \mathrm{a}$ & $2,826 \mathrm{a}$ \\
\hline
\end{tabular}

${ }^{1}$ Para cada período de armazenamento, médias seguidas pela mesma letra na coluna não diferem estatisticamente entre si, pelo teste de Tukey ao nível de $5 \%$ de probabilidade.

Outro fator importante a ser considerado no presente estudo é o tempo gasto no processo de secagem. Como a temperatura de $43{ }^{\circ} \mathrm{C}$ (maior temperatura utilizada no estudo) foi a que propiciou melhores resultados, pode-se inferir que o principal problema encontrado nas condições de secagem testadas foi o tempo gasto na secagem das sementes e não propriamente a temperatura utilizada. $\mathrm{Na}$ análise de regressão dos resultados de germinação e de envelhecimento acelerado em função do tempo gasto nos diferentes métodos de secagem (Figura 5) observa-se queda linear da qualidade fisiológica das sementes com o aumento do tempo de secagem, tanto na avaliação realizada logo após a secagem como naquela realizada após 270 dias de armazenamento. Assim, pode-se afirmar que sementes de pinhão manso não devem ser submetidas à secagem muito lenta e que o tempo de secagem até 42 horas não é prejudicial à qualidade das sementes. Peske (2005) afirma que as sementes devem permanecer úmidas o menor tempo possível, pois o alto teor de água é o fator que mais influencia na qualidade fisiológica da semente durante o armazenamento. Segundo este mesmo autor, sementes com teor de água de $20 \%$ não devem permanecer mais de 24 a 48 horas sem secar, salvo quando armazenadas em silos com sistema de aeração adequado.

\section{CONCLUSÕES}

Sementes de pinhão manso podem ser secadas ao sol e sob temperaturas de 33 e $43{ }^{\circ} \mathrm{C}$.

Temperatura de $43{ }^{\circ} \mathrm{C}$ proporciona menor tempo de secagem e melhor germinação e vigor de sementes de pinhão manso.

Secagem à sombra é prejudicial à qualidade de sementes de pinhão manso. 


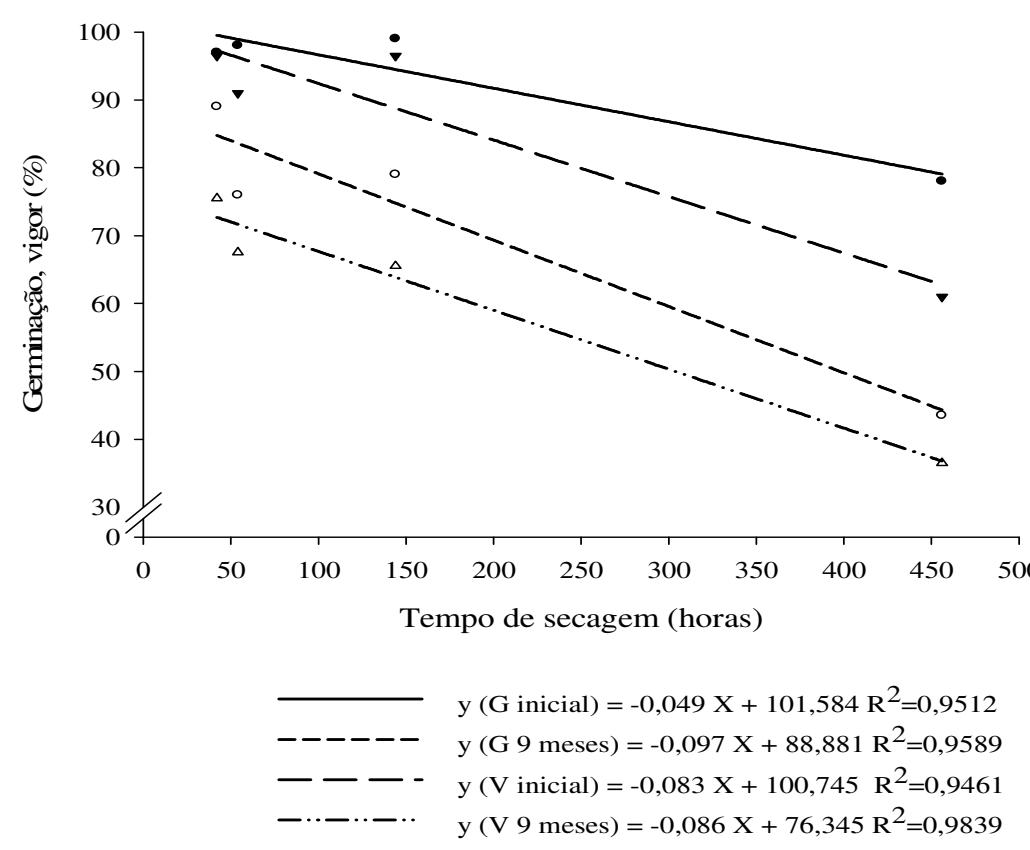

FIGURA 5. Germinação e envelhecimento acelerado de sementes de pinhão manso, antes e após o armazenamento, em função do tempo gasto na secagem.

\section{AGRADECIMENTOS}

À FAPEMIG e ao CNPq pelo financiamento do projeto e concessão de bolsas.

\section{REFERÊNCIAS}

AHRENS, D.C.; VILLELA, F.A.; DONI FILHO, L.; Secagem estacionária de sementes de aveia-branca (Avena sativa 1.) empregando diferentes temperaturas do ar. Revista Brasileira de Sementes, v.22, n.2, p.6-11, 2000.

AHRENS, D.C.; LOLLATO, M.A. Qualidade de semente de feijão e velocidade de secagem ao sol e em secador de fluxo contínuo. Informativo ABRATES, v.5, n.2, p.52, 1995.

BARBEDO, C.J.; BILIA, D.A.C.; FIGUEIREDORIBEIRO, R.C. Tolerância à dessecação e armazenamento de sementes de Caesalpinia echinata Lam. (pau-brasil), espécie da Mata Atlântica. Revista Brasileira de Botânica, v.25, n.4, p.431-439, 2002.

BRASIL. Ministério da Agricultura e Reforma Agrária. Regras para análise de sementes. Ministério da Agricultura, Pecuária e Abastecimento. Secretaria de Defesa Agropecuária. Brasília, DF: Mapa/ACS, 2009.
$395 p$.

CAVARIANI, C. Secagem estacionária de sementes de milho com distribuição radial do fluxo de ar. 1996. 85f. Tese (Doutorado em Produção Vegetal) - Esalq-USP.

EICHELBERGER, L.; MAIA, M.S.; PESKE, S.T.; MORAES, D.M. Efeito do retardamento da secagem na qualidade fisiológica de sementes armazenadas de azevém anual. Pesquisa Agropecuária Brasileira v.38, n.5, p.643-650, 2003.

GARCIA, D.C.; BARROS, A.C.S.A.; PESKE, S.T.; MENEZES, N.L. A secagem de sementes. Ciência Rural, v.34, n.2, p.603-608, 2004.

HARRINGTON, J.F. Drying storaging and packaging seeds to maintain, germination and vigor. Proc. Short Course for Seedsmen. Seed Technology Laboratory, Mississippi State, Part. 1. 1959.

HARRINGTON, J.F. Seed storage and logevity. In: KOZLOWSKI, T.T. Seed biology. New York: Academic, v.3, 1972, p.145-245.

JOKER, D.; JEPSEN, J. Jatropha curcas L. Seed Leaflet, Humleback, Denmark, n.83, p.1-2, Aug. 2003.

LUO, C.W.; LI, R.; CHEN, Y.; SUN, Y.Y. Floral display 
and breeding system of Jatropha curcas L. Forestry Studies in China, v.9, n.2, p.114-119, 2007.

MAGUIRE, J.D. Speed of germination-aid in selection and evaluation for seedling emergence and vigor. Crop Science, v.2, n.2, p.176-177, 1962.

MAIA, M. Secagem de sementes de azevém anual (Lolium multiflorum Lam.) com ar ambiente forçado. 1995. 108f. Tese (Doutorado em Ciência e Tecnologia de Sementes) - UFPel.

MARCOS FILHO, J. Teste de vigor: importância e utilização. In: KRZYZANOWSKI, F.C.; VIEIRA, R.D.; FRANÇA NETO, J.B. (Ed.). Vigor de sementes: Conceitos e Testes. Londrina: ABRATES, 1999. Cap.1, p.1-21.

MARCOS FILHO, J. Fisiologia de sementes de plantas cultivadas. Piracicaba: FEALQ, 2005. 495p.

MARTINS, C.C.; MACHADO, G.M.; CAVASINI, R. Temperatura e substrato para o teste de germinação de sementes de pinhão manso. Ciência e Agrotecnologia, v.32, n.3, p.863-868, 2008

MIRANDA, L.C.; DA SILVA, W.R.; CAVARIANI, C. Secagem de sementes de soja em silo com distribuição radial do fluxo de ar. I. Monitoramento físico. Pesquisa Agropecuária Brasileira, v.34, n.11, p.2097-2108, 1999.

MORAIS, E.B.S.D. Padronização de teste de germinação e qualidade de sementes de Pinhão manso (Jatropha curcas L.) durante o armazenamento. 2008. 103f. Dissertação (Mestrado) Universidade Estadual de Montes Claros, Janaúba, MG.
MOSHKIN, V.A. Castor. New Delhi: Amerind, 1986. $315 \mathrm{p}$

PESKE, S.T. Sementes: fundamentos científicos e tecnológicos. 2.ed. Pelotas: Ed. Universitária, 2006. $470 \mathrm{p}$.

POPINIGIS, F. Fisiologia da semente. Brasília, DF: AGIPLAN, 1985. 289p.

SAEG - Sistema para Análises Estatísticas, Versão 9.1: Fundação Arthur Bernardes - UFV-Viçosa, 2007.

SHAO-CHUN, M.; ZHU-YING, L.; CONG, L. Application of biodiesel produced from Jatropha curcas L. seed oil. Zhongguo Youzhi / China Oils and Fats, v.32, n.7, p.40-42, 2007.

SIRISOMBOON, P.; KITCHAIYA, P. Physical properties of Jatropha curcas L. kernels after heat treatments. Biosystems Engineering, v.102, n.2, p.244-250, 2009.

ULLMANN, R.; RESENDE, O.; SALES, J.F.; CHAVES, T.H. Qualidade das sementes de pinhão manso submetidas à secagem artificial. Revista Ciência Agronômica, v.41, n.3, p.442-447, 2010.

VIEIRA, R.D.; KRZYZANOWSKI, F.C. Teste de condutividade elétrica. In: KRZYZANOWSKI, F.C.; VIEIRA, R.D.; FRANÇA-NETO, J.B. (Ed.). Vigor de sementes: conceitos e testes. Londrina: ABRATES, 1999. cap.4, p.1-26. 